\title{
Acute Myocardial Infarction as the Initial Clinical Manifestation of Pernicious Anemia
}

Leonardo Marostica Alves Silva, ${ }^{(\mathbb{1})}$ Assis Xavier da Silva Barros Junior, ${ }^{\circledR}$ João Antonio de Toledo Galina, ${ }^{\mathbb{D}}$ Alexandre Rodrigues, ${ }^{(0)}$ Igor Ribeiro de Castro Bienert, ${ }^{(1)}$ Pedro Beraldo de Andrade

Faculdade de Medicina de Marília, Marília, SP - Brazil

\section{Introduction}

Despite its lower prevalence in young individuals, acute myocardial infarction (AMI) causes significant morbidity and socioeconomic impact when occurs in this group. In 2010, considering only the hospitals accredited by the Brazilian Unified Health System, there were 8,368 hospitalizations and 2,556 deaths from ischemic heart diseases among patients younger than 40 years. ${ }^{1}$ Although hospitalization rates are lower at this age range, the importance of this theme lies mainly in the absolute numbers of cases.

Acute coronary syndrome (ACS) in young patients has characteristics that differ from older patients. Although coronary atherosclerotic disease is a common cause, the prevalence of AMI without obstruction in the coronary arteries is higher among the young. ${ }^{2}$ Among the causes of AMI without atheromatous disease, thromboembolism is a differential diagnosis, with hypercoagulability correlated with formation of coronary embolism. Thus, it is important to identify alternative etiologies in the approach of AMI in young patients since modifiable factors can be diagnosed and treated. In this article, we present a case in which an autoimmune disease may be the cause of ACS in a young patient with few attributable risk factors for cardiovascular disease.

\section{Clinical case}

Male patient, 29 years old, non-smoker, non-diabetic, with hypertension controlled with monotherapy, with

\section{Keywords}

Myocardial Infarction/economics; Anemia,Pericious; Homocysteine; Mortality \& Morbidity; Percutaneous Coronary Intervention/economics. vitiligo and compensated hyperthyroidism, treated with propylthiouracil. The patient was admitted to the emergency department with angina-like, exertional chest pain that began more than 24 hours during the first medical visit. Electrocardiography revealed signs of transmural myocardial infarction of lateral wall in progression. The patient showed an important reduction of pain intensity, but was still symptomatic, and received anti-ischemic treatment (beta-blocker, intravenous nitrate), antithrombotic treatment (acetylsalicylic acid, ticagrelor, unfractionated heparin), and referred for emergency coronary angiography, which showed thrombotic occlusion of the left marginal artery (Figure 1), and no evidence of atheromatous plaques in the other coronary arteries.

Percutaneous coronary intervention with stent implantation was performed, with concomitant administration of glycoprotein iib/iiia inhibitors due to the high thrombus load, with restoration of epicardial blood flow (TIMI 3). Echocardiography of control revealed hypokinesia of the inferolateral wall, with mildly abnormal ejection fraction (47\%). The patient remained asymptomatic after the procedure; tests for thrombophilia were performed, with normal results. Renal function and thyroid function were preserved, and the patient had macrocytic anemia $(\mathrm{Hb} 10.0 \mathrm{~g} / \mathrm{dL} /$ VCM 117fl). The patient was discharged with optimized therapy for secondary prevention and a plan of outpatient follow-up for investigation of anemia.

After 30 days, the patient was referred from a health care center presenting with the skin pale and complete blood count compatible with severe anemia (hemoglobin of $5.6 \mathrm{~g} / \mathrm{dL}$ ), with macrocytosis (MCV 123fl), without hemodynamic instability or signs of bleeding. Upper endoscopy was performed and showed a pattern of atrophic gastritis, which was later confirmed by biopsy

Mailing Address: Leonardo Marostica Alves Silva

Faculdade de Medicina de Marilia - Cardiologia - Av. Monte Carmelo, 800. Postal Code: 17519-030, Marília, São Paulo, SP - Brazil.

E-mail: leomarostica@famema.br 


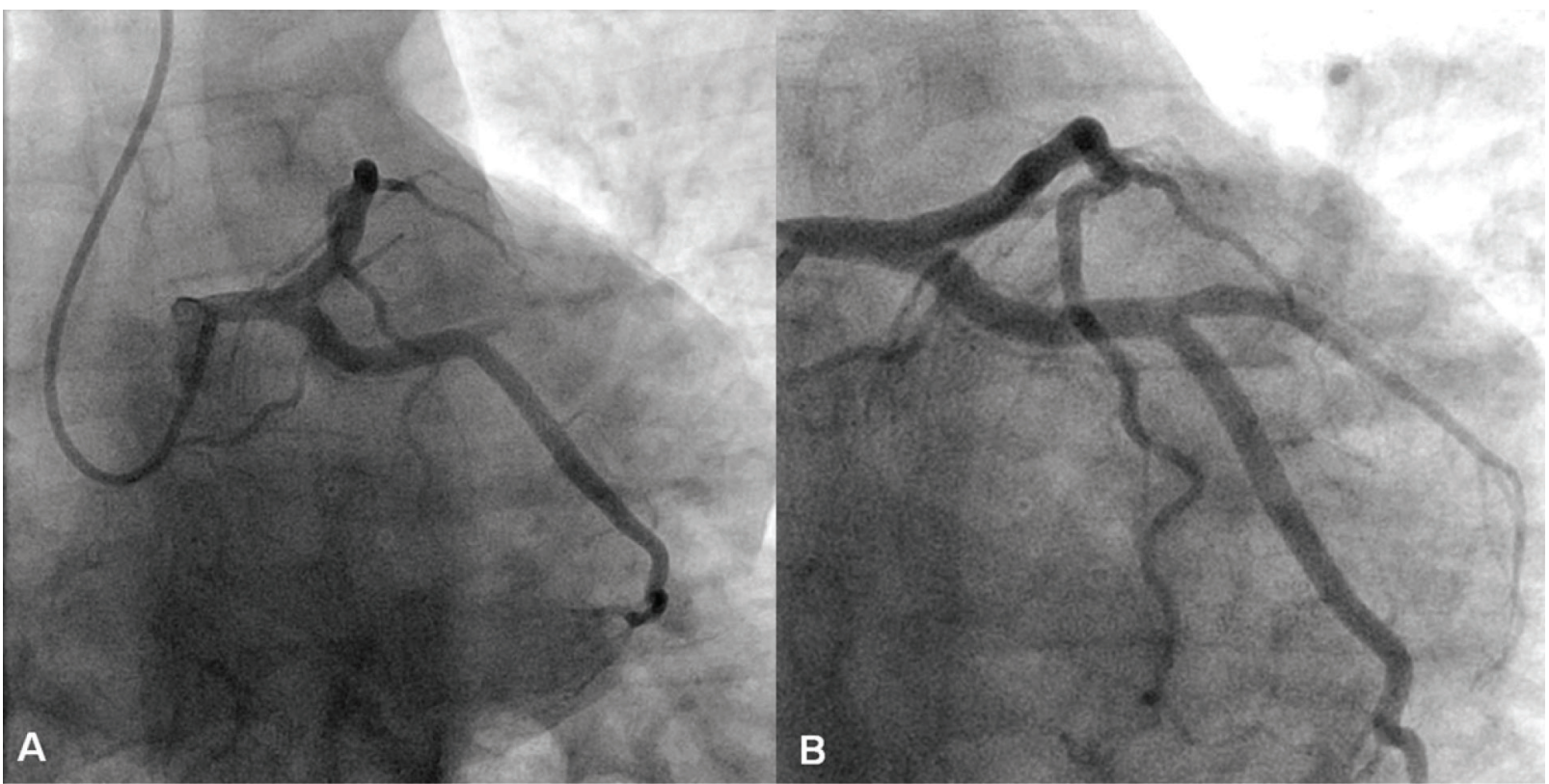

Figure 1 - A) Thrombotic occlusion in the left marginal artery; B) Post-percutaneous coronary intervention with stent implantation.

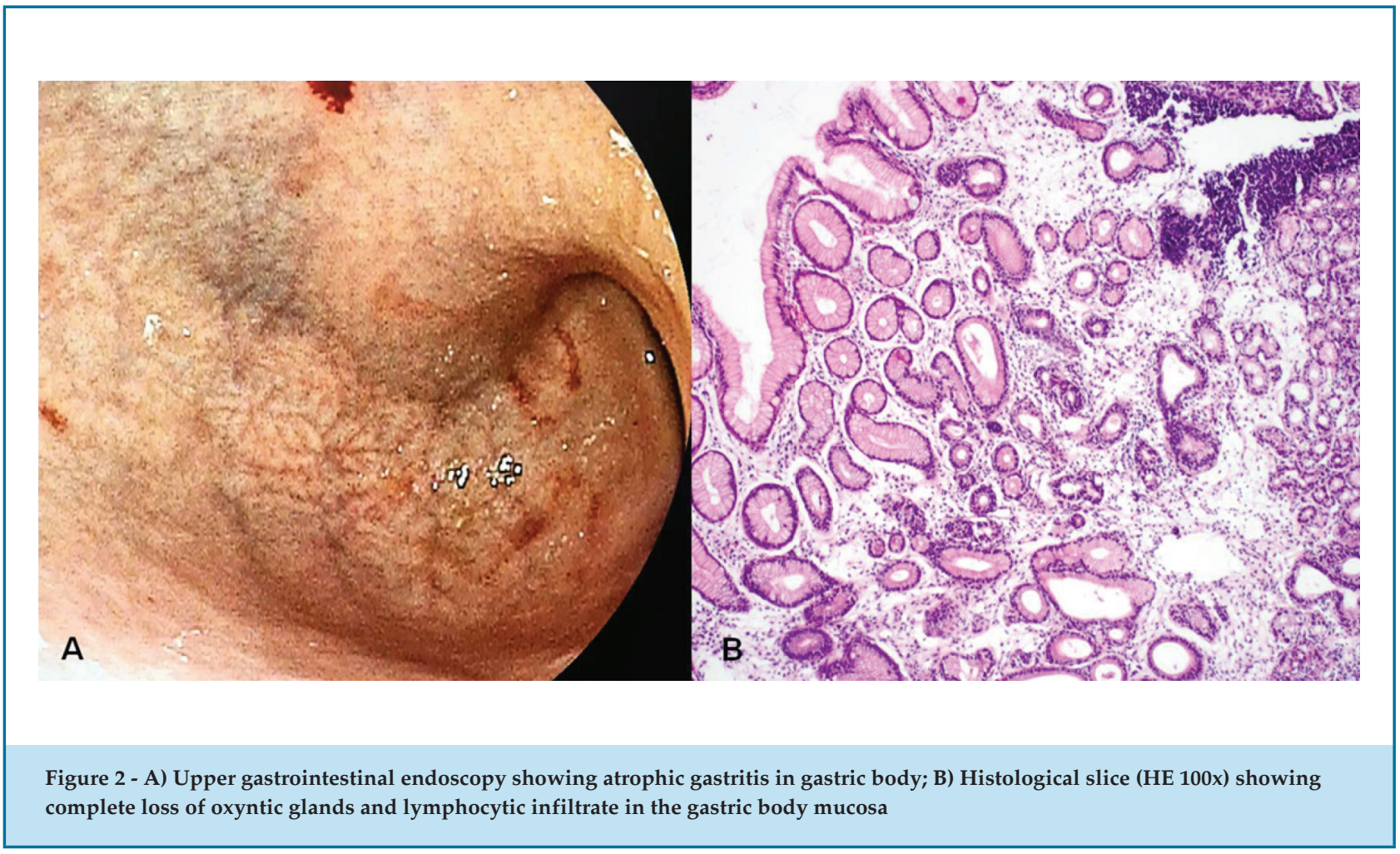


(Figure 2). Blood tests showed undetectable levels of vitamin B12 $(<83 \mathrm{pg} / \mathrm{mL})$ and increased homocysteine levels by approximately 10 times the upper reference level (155.85 mmol/L). These results led to the diagnosis of pernicious anemia, and the therapy with intramuscular injection of vitamin B12 was started as recommended. After one month of therapy, patient was asymptomatic, the levels of homocysteine decreased to $8.44 \mathrm{mmol} / \mathrm{L}$, with normalization of complete blood count (hemoglobin $14.3 \mathrm{~g} / \mathrm{dL}$ and MCV 82.8fl).

\section{Discussion}

Pernicious anemia is the most common cause of vitamin B12 deficiency. ${ }^{3}$ It is an autoimmune disease associated with atrophic gastritis characterized by synthesis of antibodies against parietal cells of the stomach, inhibiting the synthesis of intrinsic factor, which is an essential binder for the absorption of cobalamin in the terminal ileum. In the intracellular milieu, vitamin B12 is the cofactor for conversion of homocysteine to methionine and tetrahydrofolate, the active form of folic acid. Thus, in case of cobalamin deficiency, the synthesis of cellular DNA is impaired, resulting in megaloblastic anemia and accumulation of homocysteine in the plasma. ${ }^{4}$

Hyperhomocysteinemia has been shown as a risk factor for cardiovascular disease, leading to atheroma plaque formation, and arterial or venous thrombosis, involving vessels of all sizes. The association between high homocysteine levels and thrombosis may be related with platelet dysfunction, thrombin generation and decreased fibrinolysis. Regarding atherosclerotic coronary disease, hyperhomocysteinemia has been associated with increased oxidative stress and proliferation of the vascular smooth muscle, resulting in endothelial injury and atheromatous plaque formation. ${ }^{5}$ Individuals with plasma homocysteine levels $12 \%$ above the upper normal limit $(15 \mathrm{mmol} / \mathrm{L})$ have a three times greater risk of developing an AMI compared with those with homocysteine levels below $10 \mathrm{mmoL} / \mathrm{L}$, even after correction for other risk factors. ${ }^{6}$ An increase by $5 \mathrm{mmoL} / \mathrm{L}$ in homocysteine levels increases the relative risk for myocardial ischemia by 1.7 times. $^{7}$

A possible relationship between hyperhomocysteinemia and coronary artery disease was initially suggested in 1976. ${ }^{8}$ However, hyperhomocysteinemia has not been established as an isolated risk factor for cardiovascular disease, considering that, so far, current evidence is not sufficient to support or reject this association. In some groups of patients, however, determination of serum levels of this amino acid may be recommended, particularly in those with few traditional risk factors, patients with premature atherosclerosis and young patients with diagnosis of AMI or stroke.

Two thirds of the cases of hyperhomocysteinemia are related with low vitamin B12 concentrarions. ${ }^{9}$ Thus, conditions that lead to low plasma cobalamin levels, such as pernicious anemia, may have close relationship with atherosclerotic or thrombotic vascular disease. Considering such association, the investigation of pernicious anemia as differential diagnosis of coronary disease in young patients.

\section{Acknowledgements}

We thank Dr. Iara Alves Coelho Sganzela and Dr. Luiz Carlos da Silva who helped us to obtain the figures.

\section{Author contributions}

Conception and design of the research: Silva LMA, Barros Jr, AXS. Acquisition of data: Silva LMA, Barros Jr, AXS, Galina JOT. Analysis and interpretation of the data: Silva LMA, Andrade PB. Writing of the manuscript: Silva LMA, Andrade PBA. Critical revision of the manuscript for intellectual content: Rodrigues A, Bienert IRC, Andrade PBA.

\section{Potential Conflict of Interest}

No potential conflict of interest relevant to this article was reported.

\section{Sources of Funding}

There were no external funding sources for this study.

\section{Study Association}

This study is not associated with any thesis or dissertation work.

\section{Ethics approval and consent to participate}

This study was approved by the Ethics Committee of the FAMEMA under the protocol number 08051019.9.0000.5413. All the procedures in this study were in accordance with the 1975 Helsinki Declaration, updated in 2013. Informed consent was obtained from all participants included in the study. 


\section{References}

1. Brasil. Ministério da Saúde. DATASUS: banco de dados. [Internet]. \{Acesso em 2019 jan 13]. Disponível em: <http://tabnet.datasus.gov.br/ cgi/deftohtm.exe?idb2011/d29.def>.

2. Agewall S, Beltrame JF, Reynolds HR, Niessner A, Rosano G, Caforio, ALP, et al. ESC working group position paper on myocardial infarction with non-obstructive coronary arteries. Eur Heart J. 2017;38(3):143-53.

3. Toh BH, van Driel, IR, Gleeson, PA. Pernicious anemia. N Engl J Med. 1997; 337(20):1441-8

4. Antony AC. Anemias megaloblásticas. In: Goldman L, Shafer AI (orgs). Cecil Medicina. 24 ed. Rio de Janeiro: Atheneu;2014. p.1230-40

5. Kuller LH, Evans RW. Homocysteine, vitamins, and cardiovascular disease. Circulation. 1998;98(3):196-9.
6. Arruda VR, von Zuben PM, Chiaparini LC, Annichino-Bizzacchi JM, Costa FF. The mutation Ala677-->Val in the methylene tetrahydrofolate reductase gene: a risk factor for arterial disease and venous thrombosis. Thromb Haemost. 1997; 77(5):818-21.

7. Nygard O, Nordrehaug JE, Refsum H, Ueland PM, Farstad M, Vollset SE. Plasma homocysteine levels and mortality in patients with coronary artery disease. N Engl J Med. 1997;337(4):230-6.

8. Clarke R, Daly L, Robinson K, Naughten E, Cahalane S, Fowler B, Graham, I. Hyperhomocysteinemia: an independent risk factor for vascular disease. N Engl J Med. 1991;324(17):1149-55.

9. Stampfer MJ, Malinow MR, Willett WC, Newcomer LM, Upson B, Ullmann $\mathrm{D}$, et al. A prospective study of plasma homocyst(e)ine and risk factor of myocardial infarction in US Phisicians. JAMA. 1992;268(7):877-81. 